\title{
On Attempts to Protect a Structure from Lightning Strikes by Enhanced Space Charge Generation
}

\author{
Vernon Cooray ${ }^{*}$ and Mihael Zitnik
}

\author{
Division of Electricity and Lightning Research, Angström Laboratory, University of Uppsala, Sweden
}

\begin{abstract}
Research conducted in laboratory on long sparks shows that the breakdown voltage of spark gaps increases the presence of corona emission from one or both of the electrodes. This observation together with other reasoning based on intuition has led some scientists to suggest the possibility of avoiding a lightning strike to a building by introducing sufficient quantities of space charge around it. In this paper the way in which the striking distance of a slim structure changes as a result of it being equipped with a network of corona generating needles is investigated. Based on the results presented in this paper one can make the following conclusions. (a) The connection of a corona element of radius $R_{c}$ on top of a tower of radius $R\left(R_{c}>R\right)$ will lead to a decrease in the striking distance of the tower. This decrease is purely a geometrical effect and the space charge generated by the corona needles may play only a minor role in reducing the striking distance. (b) Neither the geometrical effect nor the space charge generated by the corona element can reduce the striking distance of a given tower below a certain critical value which depends only on the charge on the stepped leader. Thus, the corona element will not be able to prevent a lightning flash terminating on the tower.
\end{abstract}

Keywords: Striking distance, space charge, dissipation arrays.

\section{INTRODUCTION}

In the presence of a background electric field grounded structures with sharp points go into corona creating a space charge around these points. In order to create corona the background electric field has to exceed a certain threshold value that depends on the sharpness of the pointed tips and their height. The presence of this space charge in the vicinity of these tips will screen it to some extent from the background electric field. If the corona discharge continues for some time the space charge may reduce the electric field at the tips of the grounded structures considerably.

In the case of a lightning strike to a grounded structure a connecting leader that rises from it usually mediates the final connection between the structure and the stepped leader. The reason for the development of the connecting leader is the increase in the electric field beyond a certain threshold at the top of the structure as the stepped leader progresses towards the ground. If the corona space charge density at the top of the structure is high it may screen the structure from the electric field generated by the stepped leader and impede the development of a connecting leader. In this paper we will investigate whether the space charge generated by a network of needles is capable of screening a structure to such an extent so as to protect it from a lightning strike.

This paper is structured as follows: First we will analyse the temporal development of the electric field at ground level generated by a thundercloud in the presence of corona. Second, we will show how the electric field at ground level

*Address correspondence to this author at the Division of Electricity and Lightning Research, Ångström Laboratory, University of Uppsala, Sweden; Tel: +46 18 4715809; Fax: +46 18 4715809;

E-mail: cooray@angstrom.uu.se will vary in the presence of corona during the passage of the leader from cloud to ground. Third we will describe and present the results of an experiment conducted in the laboratory to evaluate the corona current generated by a cluster of needles as a function of the background electric field. Fourth, we will apply the said experimental data to understand the lightning performance of a tower on top of which is placed an array of corona producing needles.

\section{EVALUATION OF THE ELECTRIC FIELD AT GROUND LEVEL IN THE PRESENCE OF CORONA}

It is a well documented fact that grounded objects with sharp points, plants and trees go into corona when the ambient electric field increases above about $1-5 \mathrm{kV} / \mathrm{m}$. Depending on the polarity of the ambient electric field the corona discharge will introduce positive or negative space charge into the surrounding space which in effect decrease the electric field at ground level. Let us now investigate the effect of corona on the electric field at ground level caused by a thundercloud. The effect of ground corona on the electric fields produced by thunderclouds has been studied previously by Chauzy and Soula [1].

The thundercloud is represented by a vertical dipole with the location of the negative and positive charge centres at 4 $\mathrm{km}$ and $8 \mathrm{~km}$, respectively, from ground level. Let us also assume that the charging process taking place inside the thundercloud can be represented by a vertical source current of strength 1A [2]. This charging current is initiated at $t=0$. The electric field produced by this thundercloud at ground level in the absence of corona is described by

$$
E_{\text {cloud }}(t)=\frac{t}{2 \pi \varepsilon_{o}}\left[\frac{1}{H_{n}^{2}}-\frac{1}{H_{p}^{2}}\right]
$$


where $H_{n}$ and $H_{p}$ are the height of the negative and positive charge centres respectively and $t$ is the time.

As the electric field at ground level increases beyond a certain critical value the small plants and trees will go into corona. The corona current density produced by them can be described by $[3,4]$

$$
J_{c o r}=c E(t)\left(E(t)-E_{o}\right)^{2}
$$

where $E(t)$ is the total electric field at ground level (i.e. the sum of the electric field produced by the thundercloud and the corona space charge) at time $t, E_{0}$ is the threshold electric field necessary for corona inception and $c=2 \times 10^{-20} \mathrm{Am} / \mathrm{V}^{3}$. Using this corona equation calculations are performed to investigate the effect of corona space charge on the electric field at ground level for several values of corona thresholds. In the calculations it is also assumed that the thickness of the corona space charge layer created by corona is less than the horizontal extent of the corona layer. Furthermore, the mobility of the ions is selected to be $1,36 \times 10^{-4} \mathrm{~m} / \mathrm{s} / \mathrm{V} / \mathrm{m}$, which is a representative value for small positive ions in air [5].

The results obtained are shown in Fig. (1). The curve 1 depicts the electric field at ground level when there is no space charge. Observe that in the presence of corona space charge the electric field will be clamped at a value between $5.0 \times 10^{3} \mathrm{~V} / \mathrm{m}-10.0 \times 10^{3} \mathrm{~V} / \mathrm{m}$ depending on the corona threshold (curves 2, 3 and 4). Now we will consider how the electric field at ground level in the presence of corona vary as a stepped leader approaches the ground. Again, the charging process in the thundercloud is assumed to start at $t$ $=0$ and the stepped leader starts propagating downwards from the cloud around $t=60 \mathrm{~s}$. The dynamic charge distribution on the stepped leader channel as it approaches the ground is identical to the one given by Cooray et al. [6] with a prospective return stroke current of $30 \mathrm{kA}$. The total electric field at ground level is the sum of the electric field produced by the charge in the thundercloud and the electric field produced by the charge deposited on the down coming stepped leader.

The results obtained with and without the space charge are shown in Fig. (2). The results show that even though the space charge can clamp the slowly varying portion of the electric field at ground level, it cannot clamp the rapidly rising electric field that occur at ground level as the stepped leader approaches it. Observe that the space charge limited electric field rises almost at the same rate as the electric field that would be present in the absence of the space charge. Indeed, in Fig. (2) the maximum fields are more or less similar in curve 1 and curve 2 . The reason for this is that the rate of generation of the corona space charge is not large enough to screen the rapidly increasing stepped leader field. However, when the electric field increases slowly, as in the case of the electric field generated by the charging process in the thundercloud, the corona space charge can screen the ground from this background electric field. This demonstrates that the efficiency of the corona space charge to screen a background electric field depends also on the rate of increase of the electric field. The next step is to investigate the effect of the space charge created by a network of needles located at the top of a tower on the striking distance. The striking distance is defined here as the height of the tip of the stepped leader from the top of the tower when a stable upward propagating leader is incepted from the tower. Before proceeding to that step however, let us evaluate the corona current generated by a set of needles exposed to a background electric field.

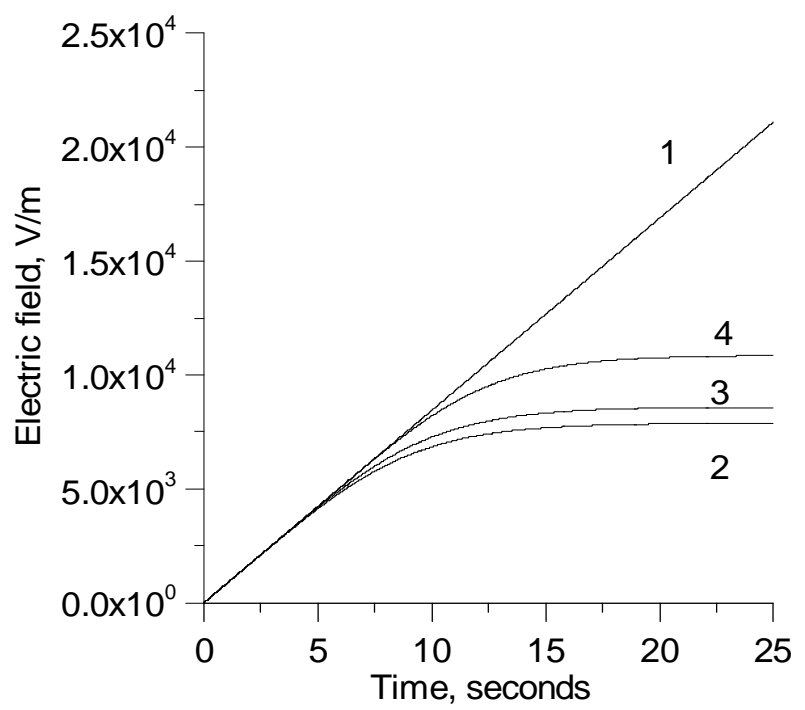

Fig. (1). The electric field at ground level produced by a thundercloud in the absence (curve 1) and in the presence (curves 2, 3 and 4) of ground corona. The threshold for corona inception is (2) $1 \mathrm{kV} / \mathrm{m}$, (3) $2 \mathrm{kV} / \mathrm{m}$ and (4) $5 \mathrm{kV} / \mathrm{m}$.

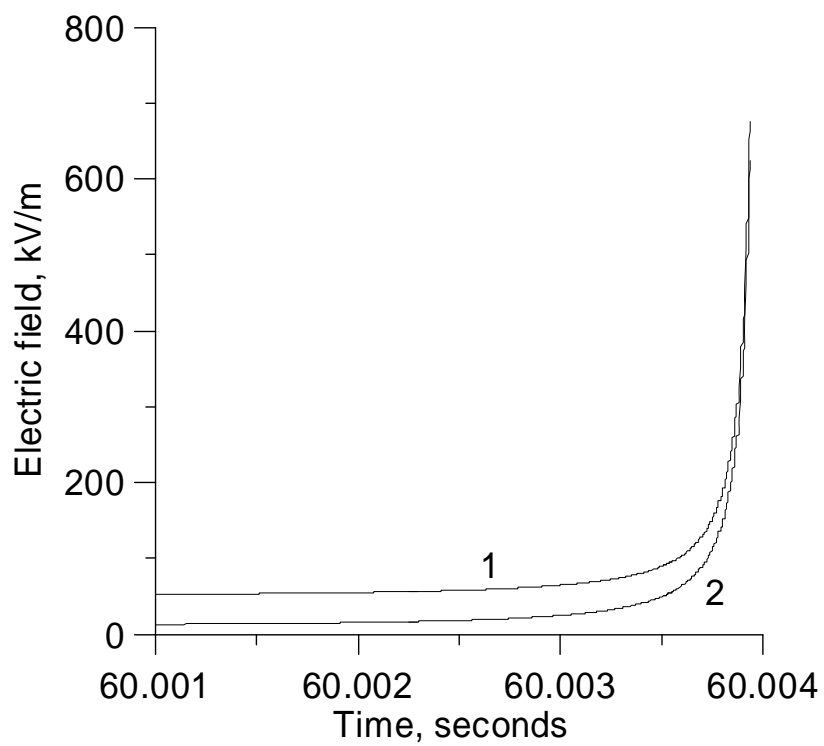

Fig. (2). The electric field produced by a thundercloud and the down coming stepped leader at ground level in the absence (curve 1 ) and in the presence (curves 2) of ground corona. The threshold for corona inception is $5 \mathrm{kV} / \mathrm{m}$. The leader is initiated at $59,996 \mathrm{sec}$ inside the cloud. The height of the negative charge center is $4 \mathrm{~km}$ and the speed of propagation of the stepped leader is $5,0 \times 10^{5} \mathrm{~m} / \mathrm{s}$. The charge distribution of the down coming leader is identical to that derived in reference [6]. 


\section{THE CORONA CURRENT GENERATED BY A CLUSTER OF NEEDLES}

The experimental setup consists of a parallel plate gap of length $0,3 \mathrm{~m}$ with $1.0 \mathrm{~m}$ diameter, Rogowski profiled electrodes. The bottom electrode of the gap was prepared in such a way that a cluster of needles can be fixed onto it. The needles used in the experiment were pointed, $2 \mathrm{~cm}$ long and 1 $\mathrm{mm}$ in diameter. The needles were arranged at the corners of $2 \mathrm{x}$ $2 \mathrm{~cm}$ adjacent squares. A dc voltage was applied to the electrode gap and the corona current generated by the needles is measured as a function of the background electric field and the number of needles in the cluster using a micro ammeter. The lower limit of the corona current that could be measured is about $1 \mu \mathrm{A}$. The results obtained are shown in Fig. (3). Observe first that the corona current increases with increasing electric field and for a given electric field the corona current increases with increasing number of needles. Note, however, that for a given electric field the corona current does not increase linearly with the number of needles. This is probably caused by the electrical screening of the needles by the adjacent ones. According to this data the corona current generated by a single needle in a cluster can be represented approximately by the equation

$I_{\text {cor }}=c_{o} E^{2}$

where $E$ is the background electric field. Of course the correct equation to represent the corona current from a needle is

$I_{c o r}=c_{o}\left(E^{2}-E_{o}^{2}\right)$

where $E_{0}$ is the corona threshold [7]. In our case, however, It is not that easy to evaluate the value of the corona threshold from the measurements since for values of $E$ close to corona threshold the corresponding corona current is at the limit of the measuring equipment. On the other hand, when the electric field is high, which is the case under study, the equation (4) reduces to equation (3) and the latter can be used in practice without significant errors.

The next problem is to evaluate the value of $c_{0}$ corresponding to a large cluster of needles. This was solved as follows. Fig. (4) depicts the corona current (in $\mu \mathrm{A}$ ) at 500 $\mathrm{kV} / \mathrm{m}$ (close to the maximum value of the background field achieved in the experiment) as a function of the number of needles. The best curve fit to the data points (crosses) can be described by the equation (solid line in Fig. 4)

$I_{c}=30.04 \log (N)+34.35$

where $\mathrm{N}$ is the number of needles in the cluster. This equation predicts that, for example, for a cluster of 1000 needles the corona current at $500 \mathrm{kV} / \mathrm{m}$ is about $240 \mu \mathrm{A}$ and for a single needle in the cluster it is about $0.24 \mu \mathrm{A}$. Of course, this number has to be considered as an order of magnitude estimation. This fixes the value of $c_{o}$ for large clusters at around $10^{-18} \mathrm{Am}^{2} / \mathrm{V}^{2}$. This value is used in the calculations to be presented in the next section.

\section{THE STRIKING DISTANCE OF A TOWER IN THE PRESENCE OF CORONA}

Let us consider a tower of height $h$ and base radius $b$. Assume that the tower can be represented by an ellipsoid. Then the radius of the tip of the tower, $R$, is given by

$R=b^{2} / h$

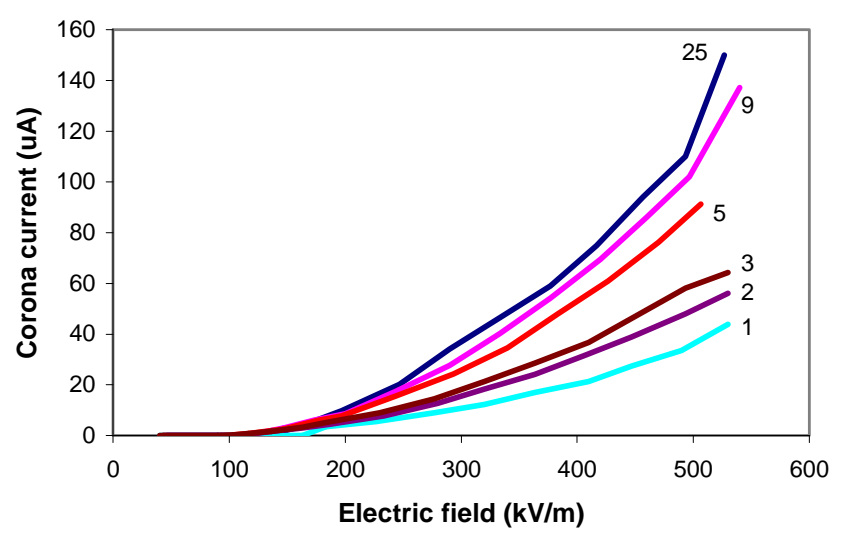

Fig. (3). The corona current as a function of the background electric field from clusters of needles. The number of needles in the cluster is shown in the diagram.

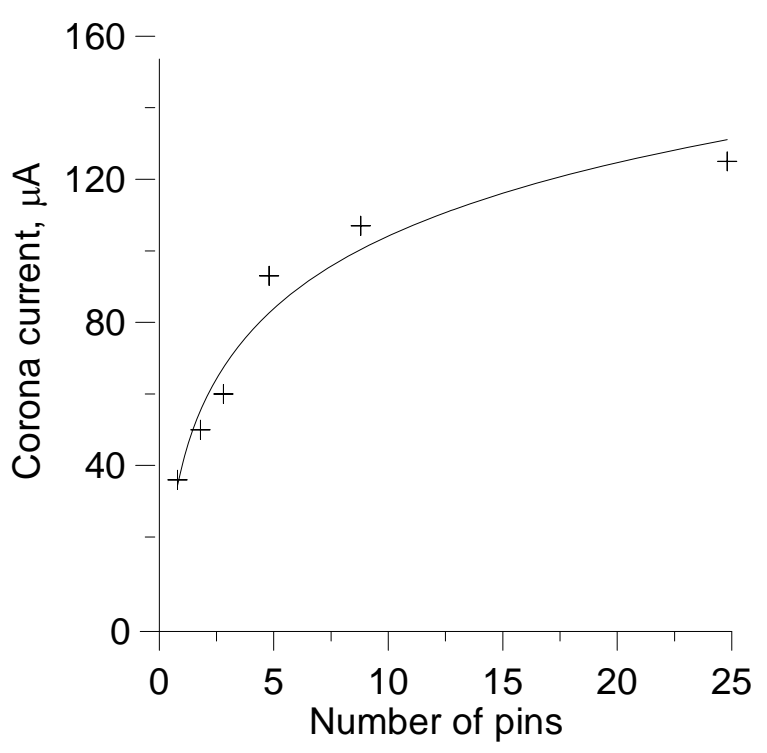

Fig. (4). The corona current at $500 \mathrm{kV} / \mathrm{m}$ as a function of the number of needles in the cluster.

Fig. (6) shows the striking distance of 10 to $100 \mathrm{~m}$ high towers as a function of the tower tip radius for stepped leaders with a prospective return stroke currents of 30,50 and $80 \mathrm{kA}$ [8]. Note that the striking distance remains constant for small radii, it starts to fall when the radius increases beyond a critical value and finally reaches a threshold value which is independent of the radius. This threshold value is equal to the value of the striking distance maintained by the said stepped leader on plane ground. This threshold value is reached when the average potential gradient between the leader tip and the tower top reaches 750 $\mathrm{kV} / \mathrm{m}$, the negative streamer threshold field. The details of the procedure used to obtain these curves are presented in reference [8].

Assume that the needles are connected onto a metal frame shaped like an ellipsoidal cap with a tip radius $R_{c}$ where $R_{c}>R$. In the calculations to be followed we assume that $R_{c}=2 \mathrm{~m}$. Let us consider the effect of placing this 'hat of needles' on top of a tower on the striking distance. 
Consider a $10 \mathrm{~m}$ high tower with a tip radius of $0.3 \mathrm{~m}$. In order to make an evaluation we have to simplify the situation somewhat. Let us disregard the needles located on the element for a moment and consider the effect of the metal cap alone on the striking distance. For simplicity replace this complex structure (ellipsoidal cap at the top of the tower) by an half ellipsoid with a tip radius equal to the radius of the cap (Fig. 5). In a given background electric field, the total electric field at the tip of the corona element (Fig. 5a) is approximately equal to electric field at the top of the equivalent ellipsoid (Fig. 5b).

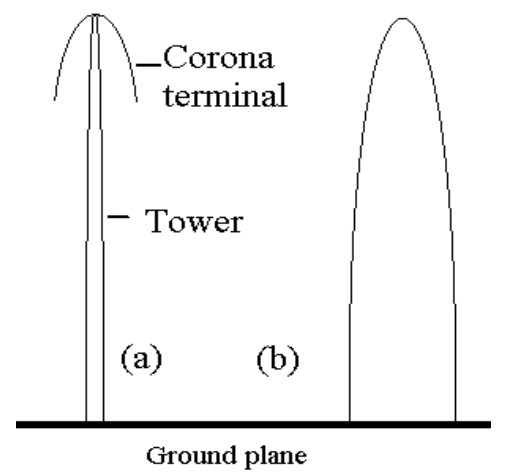

Fig. (5). (a) The tower and the corona terminal. (b) The semiellipsoid representing the complex body.

With the simplification described above, one can see from Fig. (6a) that the effect of connecting the corona element is to reduce the striking distance from about $90 \mathrm{~m}$ to about $53 \mathrm{~m}$ in the case of a $30 \mathrm{kA}$ prospective return stroke current. Similarly, if the initial height of the tower is $20 \mathrm{~m}$ the striking distance will reduce from about $118 \mathrm{~m}$ to $53 \mathrm{~m}$. In the case of a $100 \mathrm{~m}$ tower the striking distance will decrease from about $205 \mathrm{~m}$ to about $53 \mathrm{~m}$. Observe that for a grounded tower and $30 \mathrm{kA}$ prospective return stroke current, the minimum striking distance that can be achieved is about $53 \mathrm{~m}$ and this is independent of the tower height. Fig. $(\mathbf{6 a}, \mathbf{b})$ show that in the case of towers of $10 \mathrm{~m}$ to $60 \mathrm{~m}$ height, the connection of a corona element of radius $2 \mathrm{~m}$ alone will reduce the striking distance to the minimum value that is possible (i.e. $53 \mathrm{~m}$ ). The space charge generated by the corona element will not make a further reduction because the minimum striking distance has been achieved already. Only in the case of $80 \mathrm{~m}$ and $100 \mathrm{~m}$ towers further reduction of the striking distance is possible. This shows that the corona needles of the corona element will have no effect on the striking distance in the case of tower heights up to $60 \mathrm{~m}$ for a prospective return stroke current of $30 \mathrm{kA}$ (or less).

Let us consider the case of a $80 \mathrm{kA}$ return stroke current. The minimum striking distance is equal to about $115 \mathrm{~m}$. From Fig. (6d) one can observe that in the case of $10 \mathrm{~m}$ tower the connection of the $2 \mathrm{~m}$ corona element will reduce the striking distance to the minimum value possible but in the case of 40,60 and $100 \mathrm{~m}$ this modification alone will not reduce the striking distance to the minimum possible value. Thus, at these heights the corona space charge generated by the element has the potential to reduce the striking distance further. Now, let us investigate this point.

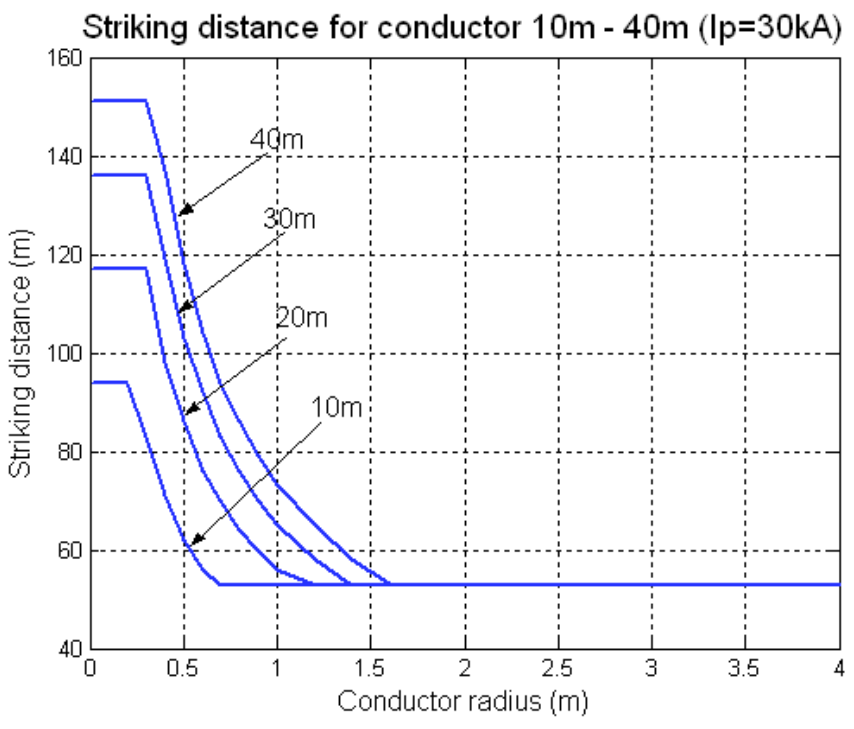

Fig. (6a). Striking distance for various conductor heights from $10 \mathrm{~m}-40 \mathrm{~m}$ with $\mathrm{I}_{\text {peak }}=30 \mathrm{kA}$.

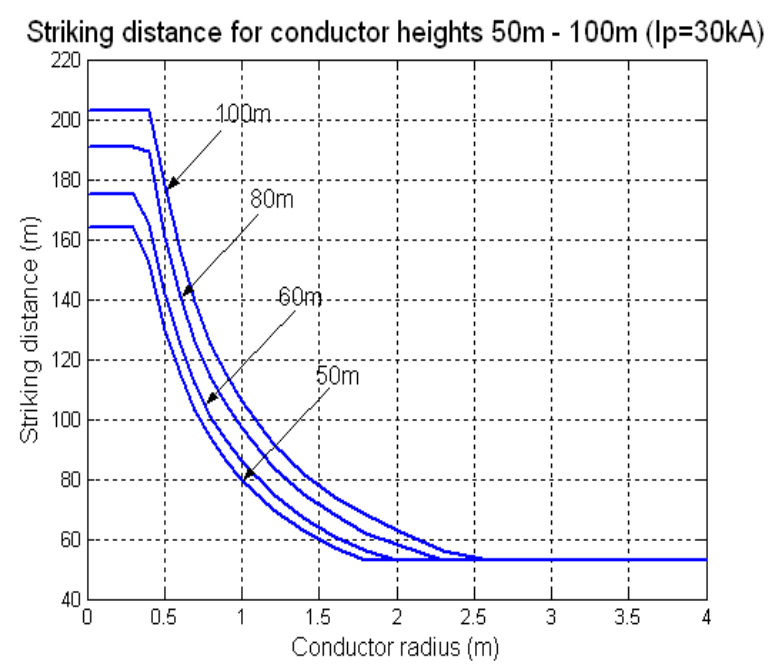

Fig. (6b). Striking distance for various conductor heights from $50 \mathrm{~m}-100 \mathrm{~m}$ with $\mathrm{I}_{\text {peak }}=30 \mathrm{kA}$.

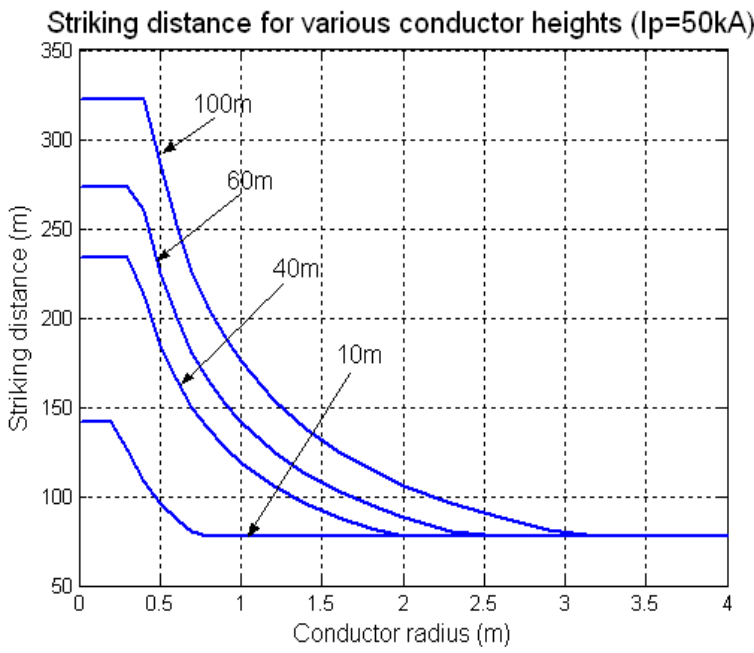

Fig. (6c). Striking distance for various conductor heights with $\mathrm{I}_{\text {peak }}=50 \mathrm{kA}$. 


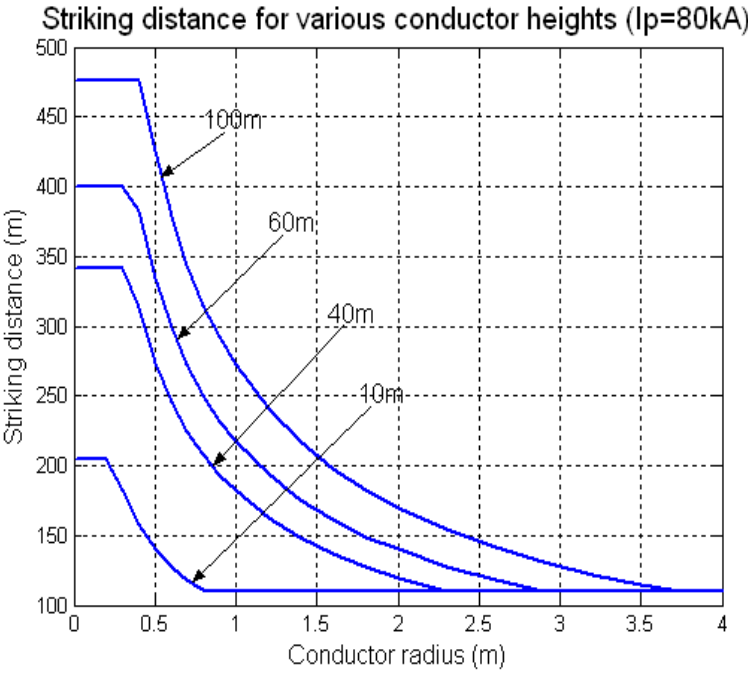

Fig. (6d). Striking distance for various conductor heights with $\mathrm{I}_{\text {peak }}=80 \mathrm{kA}$.

It is not an easy task to evaluate the screening effect of space charge generated by a set of needles since the space charge is continuously generated at the needles and it is drifting in a complex manner under the influence of the total (back ground plus space charge generated electric field) electric field. However, the calculations can be simplified significantly by adopting a particular distribution for the set of needles as follows. Consider a grounded semi-ellipsoid with the base at ground level and immersed in a uniform background electric field. Let $E\left(\eta_{o}, \theta\right)$ be the electric field normal to the surface of the ellipsoid where $\eta_{0}$ and $\theta$ are two of the ellipsoidal coordinates. The surface charge density on the surface of the ellipsoid is proportional to this normal electric field. This surface charge distribution creates a uniform electric field equal in magnitude but opposite in sign to the background electric field inside the ellipsoid. The maximum electric field on the ellipsoid is reached at the location $\theta=0$. Let us denote that by $E\left(\eta_{0}, 0\right)$. We assume that corona needles are distributed over the whole surface of the ellipsoid and the density of needles, $N\left(\eta_{o}, \theta\right)$, on the surface of the ellipsoid is given by

$N\left(\eta_{o}, \theta\right)=K \frac{E\left(\eta_{o}, 0\right)}{E\left(\eta_{o}, \theta\right)}$

where $K$ is the density of needles at the top of the ellipsoid (i.e. $\theta=0$ ). Thus the distribution of the surface charge density in the space charge layer generated by the needles during the time interval between $t$ and $t+\delta t$ is given by

$\sigma\left(\eta_{o}, \theta, t\right)=c_{o} N\left(\eta_{o}, \theta\right)\left\{E\left(\eta_{o}, \theta, t\right)\right\}^{2} \delta t$

where $E\left(\eta_{o}, \theta, t\right)$ is the electric field on the surface of the ellipsoid at time $t$. Substituting from (7) one obtains

$\sigma\left(\eta_{o}, \theta, t\right)=c_{o} K E\left(\eta_{o}, 0, t\right) E\left(\eta_{o}, \theta, t\right) \delta t$

In our calculations it is assumed that $K=1000 / \mathrm{m}^{2}$. Equation (9) shows that the charge density of the space charge layer vary in a manner identical to the surface charge density induced on an ellipsoid immersed in a uniform electric field. In our calculations we also assume that as the space charge layer expands due to ion drift it will maintain the shape of an ellipsoid, which is also a simplifying approximation. The electric field, both inside and outside the space charge layer, produced by a space charge layer having an ellipsoidal shape and having a space charge density variation identical to that of (9) is known [9]. Now we are ready to investigate the effect of needles.

As we have mentioned previously, for a $30 \mathrm{kA}$ current, the corona space charge generated by the needles in the corona element does not play a role and the full reduction in the striking distance is realised purely due to the geometrical effect (i.e. increasing the tower tip radius to $2 \mathrm{~m}$ ). However, further reductions are possible for a $80 \mathrm{kA}$ prospective return stroke current in the case of towers of heights in the range of 40 to $100 \mathrm{~m}$.

Fig. (7) shows the evolution of the electric field at the top of a $60 \mathrm{~m}$ tower during the descent of a stepped leader associated with a $80 \mathrm{kA}$ prospective return stroke current. Results are given both in the presence and absence of needles. In the calculation it is assumed that the leader trajectory, assumed to be vertical, is located directly over the tower. Observe the effect of the space charge in reducing the electric field at the top of the tower. A tower with a tip radius of about $2 \mathrm{~m}$ will launch a connecting leader when the electric field at the tower top is about $3,0 \times 10^{6} \mathrm{~V} / \mathrm{m}$. Thus, a tower without the space charge will launch a connecting leader before a tower with similar geometry but with space charge at the tower top. However, the space charge controlled field does not lag far behind the field that would be present in the absence of the space charge. For example, the difference in the leader tip height from the tower top when the electric field at the tower top reaches the critical electric field of $3.0 \times 10^{6} \mathrm{~m} / \mathrm{s}$ in the presence and in the absence of space charge is no more than two meters. Thus, the reduction in the striking distance caused by the space charge is no more than a few meters. Calculations similar to these were performed for other tower heights and prospective return stroke heights. These results show that the reduction in the striking distance is mainly a geometrical effect and the space charge generated by the corona element will play only a minor role in it. It is important to note that in our calculation the number of corona needles assumed to be located on the tower is much larger than the number of needles in corona elements used in practice. Thus, we may have overestimated the effects of space charge in our calculations. Observe also that the geometrical effect alone or the combined effect of space charge will never be able to reduce the striking distance to zero. In other words, the artificial generation of the space charge will not be able to protect a structure from a lightning strike.

As explained above the connection of a corona element at the top of a tower will change the tip of the tower from a sharp one to a blunt one. One impact of this change in the shape of the tower top would be the reduction in the number of upward flashes. For example, for a $30 \mathrm{~m}$ tower of $0,3 \mathrm{~m}$ tip radius the background electric field necessary to launch a leader is equal to about $62 \mathrm{kV} / \mathrm{m}$ [10]. However, if we change the radius of the top of the tower to $2 \mathrm{~m}$ the background electric field necessary for the initiation of a 
stable leader will increase to $240 \mathrm{kV} / \mathrm{m}$. This shows that one can reduce the number of upward initiated flashes by increasing the radius of the tower top by connecting an ellipsoidal cap (or a spherical cap) with a radius larger than the radius of the tower. This observation supports the Golde's [11, 12] suggestion that corona elements connected on tall towers will inhibit upward lightning flashes by modifying the geometry of the tower tip from a sharp one to a blunt one.

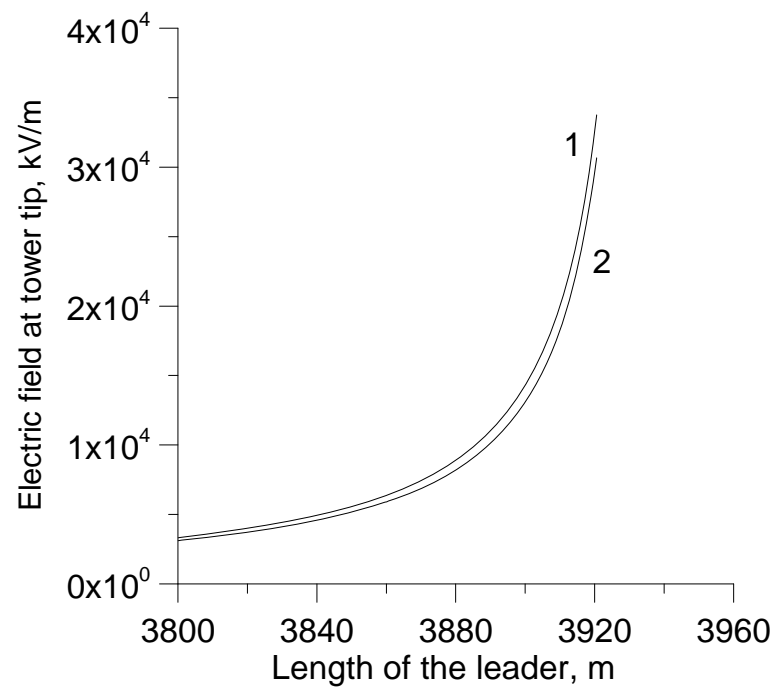

Fig. (7). The evolution of the electric field at the top of a $60 \mathrm{~m}$ tower located below the stepped leader trajectory as the stepped leader propagates towards the ground. Curve (1) shows the evolution of the electric field in the absence of space charge and the curve (2) depicts the electric field in the presence of space charge. The radius of the tower tip is $2 \mathrm{~m}$.

If the element contains corona-producing needles the resulting space charge may push the threshold background field necessary for the initiation of upward flashes even higher. The geometrical effect dominates the space charge effects, however.

\section{CONCLUSIONS}

Based on the results presented in this paper one can make the following conclusions. (a) The connection of a corona element of radius $R_{c}$ on top of a tower of radius $R\left(R_{c}>R\right)$ will lead to a decrease in the striking distance of the tower. This decrease is purely a geometrical effect and the space charge generated by the corona needles may play only a minor role in reducing the striking distance. (b) Neither the geometrical effect nor the space charge generated by the corona element can reduce the striking distance of a given tower below a certain critical value which depends only on the charge on the stepped leader. Thus, the corona element will not be able to prevent a lightning flash terminating on the tower.

\section{ACKNOWLEDGEMENT}

Declared none.

\section{CONFLICT OF INTEREST}

Declared none.

\section{REFERENCES}

[1] Chauzy S, Soula S. Ground coronae and lightning. J Geophys Res 1989; 94(13): 115-26.

[2] Moore CB, Vonnegut B. The Thundercloud, Lightning. In: Golde RH, Ed. New York: Academic Press, vol. 1, 1977.

[3] Whipple FJW, Scrase FJ. Point discharge in the electric field of the earth. Geophys Mem Lond 1936; 68: 1-20.

[4] Standler RB, Winn WP. Effects of coronae on electric fields beneath thunderstorms. Meteorol Soc 1979; 105: 285-302.

[5] Cobine JD. Gaseous conductors. Dover Publication Inc: New York 1957.

[6] Cooray V, Rakov V, Theethayi N. The lightning striking distanceRevisited. J Electrostat 2007; 65: 336-41.

[7] Chalmers JA. Atmospheric electricity. Pergammon Press: London 1967.

[8] Cooray V, Theethayi N. The striking distance of lightning flashes and the Early Streamer Emission (ESE) hypothesis. J Electrostat 2007; 65: 336-41.

[9] Moon P, Spencer DE. Field theory for engineers. D. Van Nostrand Company, Inc., New Jersey: Princeton 1961.

[10] Lalande P. Study of the lightning stroke conditions on a grounded structure. Doctoral Thesis. A publication of Office National d'Etudes et de Recherches A'erospatiales (ONERA) 1996.

[11] Golde RH. The Lightning Conductor, Lighnting Protection. In: Golde RH, Ed. Lightning. Academic Press: USA 1977; vol. 2.

[12] Mousa AM. The applicability of lightning elimination devices to substations and power lines. IEEE Trans Power Deliv 1998; 13: $1120-7$. 